\title{
Improving the Sense of Gain of Graduate Students in Food Science
}

\author{
Youling Wan (iD) and Zhiming Guo iD \\ School of Food and Biological Engineering, Jiangsu University, Zhenjiang 212013, China \\ Correspondence should be addressed to Youling Wan; wanyouling@ujs.edu.cn and Zhiming Guo; guozhiming@ujs.edu.cn
}

Received 21 May 2021; Accepted 10 June 2021; Published 14 June 2021

Academic Editor: Biao Yuan

Copyright (C) 2021 Youling Wan and Zhiming Guo. This is an open access article distributed under the Creative Commons Attribution License, which permits unrestricted use, distribution, and reproduction in any medium, provided the original work is properly cited.

\begin{abstract}
Improvement of the sense of gain as an internal driving force is the key factor to improve the training quality of graduate students in food science. Utilizing Jiangsu University graduate students majoring in food science as research samples, this study analyzed the present situation of the "sense of gain" demand. We analyzed the reasonable appeals of graduate students during their study based on fully respecting and advocating students' right of speech, listened to their opinions and suggestions on higher education, analyzed the main contradictions, and further put forward a series of countermeasures. For improving the graduate students' sense of gain during the period of study, it is necessary to improve the training quality from the following five aspects: constructing high-quality courses, cultivating people's responsibilities, implementing "soft elimination" of training links, carrying out diversified extracurricular activities, and developing comprehensive quality. This research is significant in improving the training quality of food science graduate students.
\end{abstract}

\section{Introduction}

The postgraduate of food major is the new force of food science and technology innovation, representing the future and hope of food industry [1]. It is helpful to encourage postgraduate to devote themselves to food innovation with more enthusiasm and write a new chapter of food development. The word "sense of gain" was first put forward by General Secretary Xi Jinping at the $10^{\text {th }}$ meeting of the Central Leading Group for Comprehensively Deepening Reform, and in the report of the $19^{\text {th }}$ National Congress of the Communist Party of China, it was emphasized again to "ensure that all the people have a greater sense of gain in the joint construction and shared development" [2]. The group of postgraduate majoring in food science has both professional characteristics and commonalities among young people. On how to enrich and develop the "sense of acquisition" of postgraduate in school, the author combs many years of management and practical experience.

To enhance the learning enthusiasm of graduate students majoring in food and fully explore their technological innovation potential [3], Jiangsu University has launched a series of incentive policies. Why is the sense of acquisition of graduate students not strong? The reason is that the connotation of the sense of acquisition is not deeply understood, the demand of graduate students is not accurate, and the policy implementation process is lack of effective methods and countermeasures.

What is sense of acquisition? The academia has not formed a unified understanding. In ancient Chinese, "get" means "get," "get" means "accept," and "sense" means "reaction in consciousness, emotion, or psychological change caused by stimulation" [4]. Some popular concepts in foreign social governance, such as "well-being" and "subjective quality of life," are similar to "sense of acquisition" [5]. Jiang Yongmu and others believe that "sense of acquisition" refers to the positive psychological feelings of the people due to "acquisition" [6]. Wang Simin and others believe that "sense of acquisition" is not only material but also spiritual, both visible and invisible. The sense of acquisition refers to the satisfaction that can be maintained for a long time due to the acquisition of the material and spiritual level, which emphasizes a kind of real acquisition based on being for me [7]. By deeply grasping the connotation of sense of acquisition, we can have a definite aim in the implementation process of improving the sense of acquisition of food science postgraduates. 
Maslow, an American social psychologist, once put forward the famous "hierarchy of needs theory," which divides people's needs into "physiological needs, security needs, belonging and love needs, respect needs, and selfrealization needs" [8]. These five needs develop from low to high. The sense of acquisition is closely related to human needs at different levels, and it is the experience of satisfying individual needs. Because the needs have the characteristics of groups, the needs of different groups are not the same, even if same group at different times, the needs are not the same, so the sense of acquisition is also different. Happiness will not fall from the sky nor is it given by others, but it is obtained through active participation and hard struggle. Therefore, the promotion strategy of food science graduate students' sense of acquisition needs to be customized.

The core literacy of Chinese students' development points out that the core literacy of students' development refers to the necessary character and key ability that should be possessed and can meet the needs of lifelong and social development. It is comprehensively manifested in nine qualities: social responsibility, national identity, international understanding, humanistic background, scientific spirit, aesthetic taste, physical and mental health, learning to learn, practice, and innovation [9]. Some studies believe that students who have "sense of acquisition" are more likely to obtain positive learning experience, so "sense of acquisition" can often further promote the acquisition of new knowledge and form a virtuous circle [10]. Students' sense of acquisition lies in that they can get more knowledge and skills, give full play to their potential, respect and develop their personality, have good moral character and strong sense of social responsibility, have harmonious interpersonal relationship and healthy mind and personality, and have relatively high satisfaction with university education.

To fundamentally improve the sense of acquisition of graduate students, we should further improve the quality of education as the target and make efforts from the demand and supply sides of education [11]. On the one hand, it is necessary to deeply understand and accurately grasp the objective needs of graduate students in the new situation, listen to their opinions and suggestions on higher education, fully respect and advocate their right to speak, and meet their reasonable demands. On the other hand, we should improve the supply level of suppliers. If the school or college can update the education concept, innovate the education form, correctly understand the reasonable suggestions of students, integrate the demands of students into education, and understand the needs of students for a better life is one of the new situations of the current higher education, then the students' sense of acquisition will be further improved [8].

\section{Materials and Methods}

What are the main sources of postgraduates' sense of acquisition? As a university, how to improve graduate students' sense of acquisition during the semester? The school of food and biological engineering of Jiangsu University has carried out extensive questionnaires and personal interviews on this issue, which objectively reflects the current education needs of food postgraduates during the semester. This section showed the investigation and data analysis on "sense of acquisition" of graduate students majoring in food.

\subsection{Questionnaire Survey}

2.1.1. Sample Distribution. Questionnaire survey and interview were arranged from late November to early December every year. The design mainly considered that the new graduate students are familiar with the postgraduate study, and the fresh graduates have initially summarized their postgraduate work and thought about their career planning. The design of the questionnaire fully considered factors such as different sources of students, grade differences, academic performance, and gender ratio, which makes the sample survey more representative and typical. Food science and engineering discipline of Jiangsu University is one of the first batches of first-class key disciplines and advantageous disciplines in Jiangsu province. In this study, the samples of full-time graduate students studying in food science major degree of Jiangsu University are selected, and the sample selection is representative. At the beginning of three consecutive years, a total of 1300 questionnaires were distributed and 1197 were recovered, with a recovery rate of $92.1 \%$. The basic characteristics of the survey sample are described in Table 1. The sample has a wide range of distribution, reasonable structure, and good representativeness.

\subsubsection{Questionnaire Statistics}

(1) Curriculum quality: in the evaluation of curriculum quality, 10 points were full, $11.4 \%$ of the students scored more than 9 points, $25.14 \%$ of the students scored $8-9$ points, $37.11 \%$ of the students scored $7-8$ points, $21.36 \%$ of the students scored $6-7$ points, and $4.98 \%$ of the students scored below 6 points; $20.72 \%$ of the students thought that the quality of public courses was higher than that of professional courses, $66.72 \%$ of the students thought that the quality of public courses was similar to that of professional courses, and $12.55 \%$ of the students thought that the quality of public courses was similar to that of professional courses. The quality of public courses is lower than that of professional courses.

(2) Enterprise practice: $29.25 \%$ of doctoral students have enterprise practice experience, $28 \%$ of academic master students have enterprise practice experience, and $53.73 \%$ of professional degree master students have enterprise practice experience. Among those without enterprise practice experience, $31.91 \%$ of doctoral students are not willing to practice in enterprises, $63.76 \%$ of academic master students are not willing to practice in enterprises, and $46.99 \%$ of professional master students are not willing to practice in enterprises.

(3) Tutor satisfaction: $34.73 \%$ of the students were satisfied with the guidance of the current tutor, $43.32 \%$ 
TABLE 1: Basic characteristics of the survey samples of graduate students majoring in food.

\begin{tabular}{lccc}
\hline Variable name & Variable type & Number & Percent (\%) \\
\hline \multirow{2}{*}{ Gender } & Male & 461 & 38.51 \\
& Female & 736 & 61.49 \\
\hline \multirow{2}{*}{ Degree category } & Academic doctoral students & 229 & 19.13 \\
& Academic postgraduates & 444 & 524 \\
\hline & Master of professional degree & 59 & 43.09 \\
& First year doctor & 53 & 4.93 \\
Graduate students in grade & Second year doctor & 48 & 4.01 \\
& Third year doctor & 384 & 32.08 \\
& First year master & 314 & 26.23 \\
& Second year master & 270 & 69 \\
\hline
\end{tabular}

of the students were relatively satisfied or generally satisfied with the guidance of the current tutor, and $9.07 \%$ of the students were not satisfied with the guidance of the current tutor. Among the students who are not satisfied with the tutor's guidance, $26.90 \%$ of them can have in-depth communication with the tutor and receive the tutor's targeted guidance twice a month or more, $32.68 \%$ of them can have in-depth communication with the tutor and receive the tutor's targeted guidance once a month, and $40.42 \%$ of them can have in-depth communication with the tutor and receive the tutor's targeted guidance once a month or less.

(4) Employment pressure after graduation: $26.05 \%$ of the students thought that there was a huge contradiction between job hunting and graduation thesis, $63.39 \%$ thought that the contradiction between job hunting and graduation thesis could be adapted, and $10.56 \%$ thought that there was no contradiction between job hunting and graduation thesis.

(5) Campus cultural activities: $51.97 \%$ of the students want more recreational and sports activities for graduate students, $75.37 \%$ of the students want more scientific research activities for graduate students (subject competition, Sino-foreign exchange), $37.63 \%$ of the students want more salon activities for mental health counseling, $42.21 \%$ of the students want more salon activities for career planning, and $5.76 \%$ of the students do not care.

(6) Analysis of gender differences: in the sample of the survey, male students accounted for $38.51 \%$ and female students accounted for $61.49 \%$, which was consistent with the proportion of male and female students in food science and engineering majors in China. Food industry was concerned with human nutrition and health and plays an important supporting role in improving people's living standards. Food majors need professional and technical talents with high engineering practice ability. Male students can play their advantages in mechanical design, engineering development, and structured scientific research. At the same time, food industry need to do food nutrition evaluation, configuration, and component analysis and detection, which can fully play the girls' meticulous and rigorous quality. By complementing each other, boys and girls contribute to food technology innovation together.

2.2. Personal Interview. According to the questions reflected in the questionnaire, some graduate students were randomly selected for one-to-one interview.

(1) Graduate students believe that the teacher's classroom content and scientific research is not closely related, lack of curriculum challenge, and students' sense of classroom acquisition is low; there are more theoretical courses, less practical courses, hope to strengthen the reform of curriculum teaching mode, add practical courses, and improve graduate students' enterprise cognition.

(2) The enterprise practice problems of professional degree master students are prominent, and they will face more unknown challenges when they join social practice. The students are not active and afraid of difficulties. The ability of graduate students to enter the enterprise has not been improved, but it affects the quality of graduation thesis, and the tutors are not at ease. The graduate students have not yet established a complete engineering thinking, and participating in the project will affect the R\&D progress of the enterprise, and the enterprise is not willing to accept graduate practice.

(3) Graduate students reflect that the daily guidance of tutors is biased towards the dialogue between "boss" and "staff," tutors tend to pursue the quality of academic guidance, and the concern and effective communication for graduate students' personal growth are not enough. Students and tutors are just "fellow researchers" in scientific research, and it is difficult to form a close relationship similar to a partner.

(4) Most of the supervisors and postgraduates control the quality of their dissertations loosely first and then tightly. Three or four months after graduation, it is 
difficult to give consideration to both job hunting and careful revision of dissertation, and the contradiction between teachers and students is easily intensified.

(5) Students' practical ability is weak in school, and the current education mechanism tends to theoretical learning, less experiential activities. It is hoped that more campus cultural practice activities will be beneficial to the improvement of comprehensive abilities, so that graduate students can participate in them personally, exercise their thinking in practical experience, strengthen their ability to distinguish right from wrong, firmly build the cornerstone of "Three Outlooks," and cultivate good moral quality [12].

\section{Results and Discussion}

According to the questionnaire survey and personal interview, graduate students are not "very satisfied" or "generally satisfied" in course teaching, enterprise practice, teacherstudent relationship, dissertation, and campus cultural activities. Their sense of achievement needs to be further improved. Combining with the characteristics of food science discipline and the general needs of graduate students, Jiangsu University has tried to introduce a series of measures to improve the sense of gain of graduate students from five aspects during the study.

3.1. Cultivate Quality Courses without Breakpoints and Improve the Sense of Gain in Postgraduate Class. Give full play to the characteristics of food engineering in Jiangsu University, attach equal importance to both theory and practice in curriculum design, and establish a professional curriculum system [13]. The classroom teaching effect is evaluated comprehensively by the students' class participation and reflection degree, and the curriculum system is optimized. To improve the quality of postgraduate courses, it is possible to strengthen the integration and refinement of diversified teaching teams through individual tracking, highlight the individual design of courses, actively explore the case discussion and interactive classroom teaching modes that are flipped between teachers and students, and put more emphasis on the learning effect of course teaching evaluation. It is divided into four stages:

(1) For the teaching team applying for the construction of high-quality courses, the project defense will be carried out to mainly examine the teaching philosophy, teaching characteristics and construction objectives of the course leader, highlight the characteristics of the course, and the realization path of improving students' ability. After passing the defense, the teaching team will enter the cultivation period of the construction of high-quality courses.

(2) For selected high-quality courses, students will be given key marks when selecting courses, and guide students to participate in the evaluation of the teaching effect. In addition, the school follow-up the whole process and set up an expert group composed of the head of discipline, the school's leader in charge, and the graduate education supervisor, to select the part of the content to listen to the class and evaluate the teaching, to check whether the design of the classroom teaching is consistent with the defense concept, students' participation in the class, and the actual teaching effect.

(3) After the lecture, the expert group will meet and evaluate on the spot, work with the teachers to continuously optimize and improve the teaching, and put forward targeted suggestions, and in the later course teaching, according to the form of the student questionnaire to view the curriculum teaching mode before and after the reform of the comparative effect.

(4) The school and college will give policy rewards to the quality courses that have passed the acceptance inspection, for example, the teaching workload increases the performance coefficient, and the course acceptance inspection is a must for the evaluation of the professional title of teaching teachers. In addition, excellent courses can open demonstration classes in the whole school, accept most teachers and students' on-site observation, give teachers more peer recognition, and better play the role of demonstration radiation of the construction results of excellent courses.

After three years of cultivation and practice, the School of Food and Biological Engineering of Jiangsu University has achieved remarkable results. It has formed key postgraduate construction courses such as special subject of food science and technology, fundamentals of food nondestructive testing, and excellent postgraduate courses such as advanced biochemistry and modern microbiology. In addition, food nondestructive detection techniques, a postgraduate course for overseas study, was selected as an excellent course taught in English in Jiangsu Province.

\subsection{Strengthen the Tutors' Moral Education and Enhance the} Graduate Students' Sense of Achievement in Scientific Research. Tutors are the first responsible person for the cultivation of graduate students, the model for the practice of scientific research and academic ethics, and the guide for the growth of graduate students [14]. To strengthen the role of mentor, we can explore the following four aspects:

(1) Establish the "eight guides" duty evaluation mechanism. Build a test platform for tutors' moral education and take the evaluation results of graduate students' tutors as an important basis for their evaluation. By standardizing the relevant assessment work of graduate tutors and highlighting the "first evaluation standard" of teachers' ethics, we can further ensure that there is no blind spot in the effective implementation of the responsibilities of tutors' moral cultivation. 
(2) Implement the old tutor annual training mechanism. It regularly organizes graduate supervisors to learn the relevant rules and regulations of the current state, province, and university through concentrated learning, expert reports, and group discussion, insists on repeated learning and multifacet learning, and carries out exchange of experience in postgraduate training. Establish the network question bank of "graduate tutor professional knowledge learning," implement tutor professional knowledge self-study on a regular basis, and effectively improve the tutor's guidance ability and guidance quality.

(3) Build an infiltrating teacher-student communication bridge to enhance the emotional communication between teachers and students. Set up graduate student information liaison in the mentor group, group liaison generally be held by a senior graduate student, effectively make up for the inadequacy of his fellow classmates' peer psychological support, a more accurate understanding of the junior graduate line information, become a mentor "right-hand man," alleviate the pressure of the teacher to students' psychological health education work, and form a good interactive mechanism between teachers and students.

(4) Set up advanced models and set up a mentor demonstration team. The construction standard of "Model Tutor Team" was issued, and columns were set up with the help of network media to publicize the characteristic practices of the demonstration team and establish the awareness of benchmarking. Give the outstanding mentor team a sense of honor and play the vanguard role of the outstanding team. Establish a dynamic assessment mechanism for demonstration teams. For the teams that have implemented it in place, award the enrollment quota; for the teams that do not meet the assessment standards, cancel the honorary title of demonstration.

\subsection{Strictly Cultivate the Link of "Soft Elimination" to Improve} the Sense of Gain of Postgraduates. Try to set up a collective thesis for master's degree and make clear the system of " $10 \%$ delay passing" for the first time to ensure the degree thesis from the source to better quality assurance. With soft elimination as the incentive measure, the internal driving force of graduate students majoring in food has been improved, so that they can better complete their studies and make scientific and technological innovations. By doing what they have done, the sense of achievement and gain has been improved. The collective thesis proposal can play a good role in promoting the department, the supervisor, and the graduate students:

(1) The faculty level to promote college (discipline) strengthens the management of the dissertation work. The opening information is publicized in advance, and the graduate education supervisors of schools and colleges can participate in the on-thespot inspection of the opening, collectively showing the scientific research progress, achievements, and level of all the same graduate students in the discipline, promoting the exchange of graduate students across research groups and research directions, and giving birth to scientific research inspiration.

(2) At the level of tutors, it encourages tutors to pay attention to students and strengthen guidance. Before the examination of the proposal, the proposal content must be examined by the tutor. When the supervisor determines the topic selection direction and research objectives, he is bound to discuss with the students for many times, including the scope and difficulty of the topic selection, research basis, research conditions, problems to be solved, technical route, and other aspects. Taking into account the existing basis and possible development level of the students, it is more conducive to the successful completion of the project.

(3) At the student level, it stimulates the graduate students to have more subjective initiative and sense of urgency, improves the students' attention to the dissertation, as well as their investment of time and energy in the dissertation, and fundamentally put an end to the past situation of "the tutor cannot find graduate students.

\subsection{Create Diversified Extracurricular Activities to Enhance} the Sense of Gain on the Campus of Graduate Students. Diversified extracurricular activities are a cup of tea for graduate students after scientific research and study, which can constantly relieve the boring pressure of the scientific research work and is a fertile soil for graduate students to improve their innovation and practice ability. The main after-school activities that we tried to carry out include the following:

(1) Strengthen the coordination and guidance of the discipline innovation forum and stimulate the enthusiasm of academic exchanges between teachers and students. Every year in November, Jiangsu University holds a forum for Chinese and foreign graduate students. Food science majors and life sciences, engineering disciplines, materials science, and other disciplines intersect. Ideas are generated through communication, and sparks are generated through collision. In 2020, it will host the Academic Innovation Forum of "Food Intelligent Testing and Processing" for Postgraduates in Jiangsu Province, break the intercollegiate barriers in food science discipline, encourage and guide cross-university academic exchanges, show themselves, build consensus, inspire, and promote each other. Through academic exchanges, the practical ability of graduate students can be improved to meet the needs of students' personalized development. 
(2) To carry out the teachers and students joint brand of sport team, actively organize a variety of interesting and diverse activities between teachers and students, guide the graduate students and teachers out of the lab and out of the studio, fitness, compete, and promote the teachers and students and brand activities as a lubricant of the scientific research work, teachers and students to cooperate with team spirit, and improve the relationship between teachers and students. Creating a new model of education with warmth and feelings is more conducive to enhancing the cohesion of the scientific research community between teachers and students.

(3) The group organization is for graduate student's career planning, fire safety drill, psychological counseling salon second class activities, to create the "graduate student psychological group counseling room" and "graduate employment entrepreneurship training rooms". [15]. To provide graduate students salon and discussion, interview skills, and entrepreneurial skills, alleviate psychological pressure and regulate mood, effective support, and help graduate students devote themselves to scientific research.

\section{Conclusion}

To improve the sense of gain of food science graduate students during their study is to improve the quality of postgraduate training, not forget the original intention of benefiting the people and the country, and make more positive contributions to the development of China's food industry and to meet people's yearning for a better life. Under the background of the new era, we should not only have a clear understanding of the training objectives and requirements of talents in the new era from the perspective of social development but also affirm the dominant position of postgraduates from the perspective of "people-centered" and attach importance to improving the sense of gain of postgraduates from the perspective of training path. Through this survey, it is found that multidimensional information feedback channels are the most direct means to obtain the effectiveness of policy implementation. Subsequently, diversified student information feedback mechanisms will be established, such as network mailbox, WeChat public number, the graduate student class group interviews, and teacher-student cadre team liaison investigation, fully understand the graduate student to the curriculum, teacher and scientific research platform, management mechanism, and other aspects of evaluation and rationalization proposal, and real innovation thinking puzzles, for example, it is necessary to strengthen the construction of scientific research platform and faculty, increase the investment in education hardware, and strengthen the Sino-foreign cooperation in running double degrees, so as to form a collaborative education and promote the development of higher quality graduate education. To take multiple measures at the same time, keep pace with the times and improve the sense of gain of food science graduate students, with full enthusiasm into the field of food science and technology innovation.

\section{Data Availability}

The data used to support the findings of this study are available from the corresponding author upon request.

\section{Conflicts of Interest}

The authors declare that they have no conflicts of interest.

\section{Acknowledgments}

The authors acknowledge the financial support provided by the Research on the Teaching Reform of Postgraduate Education in Jiangsu Province, Research on the Planning and Development of Higher Education in Jiangsu University (G201912), Project of Evaluation Committee of Jiangsu Institute of Higher Education (2020-Y04), and Outstanding Young Teachers of Blue Project in Jiangsu Province.

\section{References}

[1] X. Cao and S. Li, "The connotation of the times of acquired sense and reference from foreign experiences," People's Forum.Academic Frontier, vol. 2, pp. 18-28, 2017.

[2] Z. Guo, X. Zou, S. Jiang, Q. Chen, and J. Zhao, "The construction of the physics course group of the food major for new engineering subjects supports the cultivation of engineering talents," Food and Machinery, vol. 34, no. 8, pp. 216-219, 2018.

[3] Y. He and F. Zuo, Research on the Path of Improving College Students' Educational Acquisition in the New Era, pp. 147-149, Beijing Education Beijing Education (Higher Education), Beijing, China, 2018.

[4] Y. Jiang and X. Zhang, "Sharing development and building a well-off society in an all-round way," Journal of Ideological and Theoretical Education, vol. 3, pp. 74-78, 2016.

[5] S. Ma and T. Zhang, "Research on the cultivation system of food professionals under the great discussion of educational thoughts," Food Industry, vol. 40, no. 3, pp. 235-237, 2019.

[6] X. Su, Q. Li, L. Miao, D. Qin, W. Wu, and C. Liu, "Exploration of the engineering ability training mechanism for food science and engineering students under the background of "new engineering"' Food and Fermentation Industry, vol. 46, no. 18, pp. 287-290, 2020.

[7] K. Wang and W. Chen, "A probe into the ways to improve the sense of educational acquisition of college students from the perspective of humanism," Journal of Huainan Teachers College, vol. 18, no. 5, pp. 132-134, 2016.

[8] S. Wang and J. Zhang: Let the people have more "sense of gain”, https://epaper.gmw.cn/gmrb/html/2015-03/14/nw.D11 0000gmrb_20150314_1-05.htm 2015.

[9] L. Wei, "Research on the cultivation of innovation and entrepreneurship ability of food majors from the perspective of "craftsman spirit"” Food Research and Development, vol. 41, no. 12, p. 241, 2020.

[10] Q. Wei, L. Li, Y. Du et al., "“Platform-project-curriculum” interaction to promote the path exploration of students' innovation ability," Food and Fermentation Industry, vol. 46, no. 7, pp. 296-300, 2020.

[11] J. Wen, "Research on AIA three-dimensional degree of acquired sense of college students in the new era," Journal of Guangzhou City Vocational College, vol. 12, no. 1, pp. 97-100, 2018. 
[12] J. Xi, "Decisive victory to build a moderately prosperous society in an all-round way, to win the great victory of socialism with Chinese characteristics in the new era-a report at the 19th National Congress of the Communist Party of China (excerpt)," Heihe Academic Journal, vol. 1, pp. 2-193, 2018.

[13] X. Yan, "Research on the sense of acquisition of contemporary college students," Journal of Guangxi Youth Leaders College, vol. 29, no. 3, pp. 18-22, 2019.

[14] X. Yang, "Cultivating newcomers of the era should pay attention to the issue of sense of gain," Journal of the Party School of Shanxi Provincial Committee of the Communist Party of China, vol. 41, no. 3, pp. 24-27, 2018.

[15] S. Yi, X. Li, H. Liu, Y. Ge, J. Li, and F. Bai, "Relying on the innovation and practice of the "four-dimensional drive" training model for food graduate students with first-class disciplines," Food Industry, vol. 41, no. 3, pp. 251-254, 2020. 